DOI 10.1007/s10600-015-1366-9

RETRACTION NOTE

\title{
Retraction Note to: Three tetranortriterpenoids from Walsura yunnanensis
}

Springer Science+Business Media New York 2015

Retraction Note to: Chemistry of Natural Compounds 2013, 48(6):1013-1016

DOI 10.1007/s10600-013-0452-0

This article has been retracted by the author Lihui Jiang because the copyright owner of the article is the Shanghai Institute of Materia Medica where the research was conducted; the author and Central South University did not contribute to the research; and no permission was obtained from the Shanghai Institute of Material Medica for the publication of the article.

The online version of the original article can be found under doi: $10.1007 / \mathrm{s} 10600-013-0452-0$

Lihui Jiang

College of Chemistry and Chemical Engineering, Central South

University, Changsha, 410083, P. R. China 